\title{
A LEITURA PELO VIÉS FOUCAULTIANO DE ANÁLISE DOS DISCURSOS: QUESTÕES SOBRE LEITURA (EM LÍNGUA MATERNA) NO LIVRO DIDÁTICO
}

\author{
DISCOURSE ANALYSIS BY FOUCAULT AS READING THEORY: READING ISSUES (IN \\ MOTHER LANGUAGE) IN THE TEXTBOOK
}

Aline Deosti ${ }^{1}$

\section{Resumo}

No Brasil, os exames oficiais de aprendizagem têm demonstrado que estudantes concluintes do nível médio têm dificuldades em interpretar texto de média complexidade. Tendo isso em vista, este estudo tem o propósito de analisar atividades referentes ao trabalho com textos presentes no Livro Didático do Ensino Médio (Cereja \& Magalhães, 2005) do Programa Nacional do Livro Didático (2009/2011 e 2012/2014). E a partir da análise, propor aplicar os conceitos teóricos da Análise do Discurso de linha francesa, em específico as noções de Foucault, às questões ligadas ao ensino e aprendizagem de leitura.

Palavras-chave: Livro didático, Leitura, Análise do Discurso Foucaultiana.

\begin{abstract}
In Brazil, the nationals learning tests has shown that students about to finish high school have problems to interpret complex texts. Having this in mind, this paper aims to analyze text activities in a Brazilian mother language textbook for Secondary Education (Cereja \& Magalhães, 2005) from the National Program of the textbook (2009/2011 e 2012/2014). And I also propose to apply the Foucault's concept of discursive formation to develop text comprehension questions.
\end{abstract}

Key words: Mother language; Reading; Education; Discursive formation

\section{Introdução}

O livro didático é, em grande parte, a única fonte de informação científica para o estudante das escolas públicas brasileiras, ademais, ele é um ou, se não, o material educativo mais utilizado na escola atualmente, além de auxiliar a prática pedagógica do professor (Carmagnani, 1999; Souza, 1999). Assim, ele funciona como meio de contribuir para o letramento crítico docente e como suporte para o desenvolvimento da autonomia do estudante.

Considerando os desempenhos dos estudantes concluintes do ensino médio em exames oficiais de avaliação da aprendizagem quanto a atividades de leitura e tendo em vista o papel fundamental do livro didático no processo de ensino $e$ aprendizagem de língua materna, este estudo tem, a princípio, o propósito de refletir sobre as questões que envolvem o ensino e aprendizagem de leitura frente à educação regular do ensino médio em escolas públicas. Para tanto traz reflexões

\footnotetext{
${ }^{1}$ UFPR/CNPq Mestrado - deosti@gmail.com
}

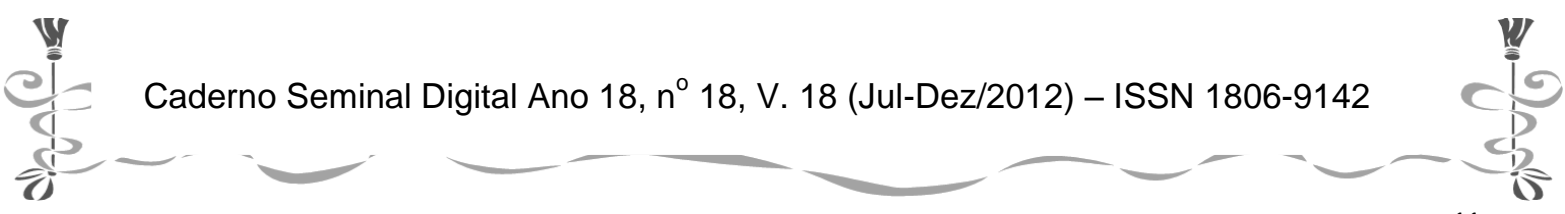




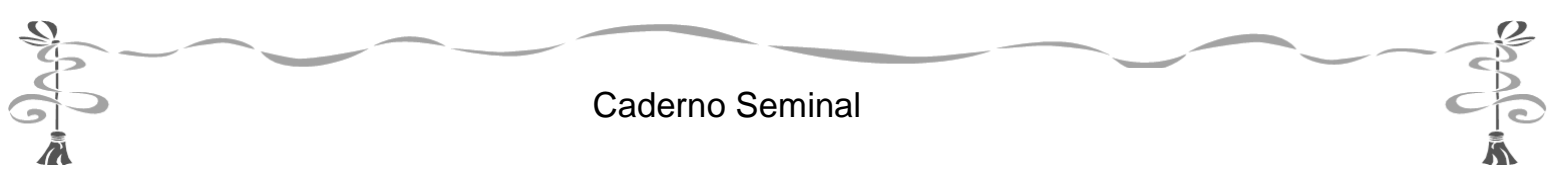

analíticas de atividades referentes ao trabalho com textos presentes no Livro Didático para o Ensino Médio (LDEM), (Cereja \& Magalhães, 2005), aprovado pelo Ministério da Educação e adotado no triênio 2009-2011 e (re)adotado recentemente em 2012 por algumas escolas do estado do Paraná. Uma vez que dentre as atividades propostas por esse livro didático é parco o trabalho voltado para a leitura textual, tenho um segundo objetivo, apresentar atividades de leitura que possam auxiliar o processo de construção de sentidos pelos estudantes por intermédio de um professor.

A proposição dessas atividades tem como base teórico-metodológica a fase arqueológica de Michel Foucault (1926/1984) circunscrita à análise do discurso francesa, especificamente as categorias que constituem a Formação discursiva (FD), entendida, nesse trabalho, como unidade determinada pela regularidade do sistema enunciativo geral ao qual está submetido um grupo de enunciados, e a Função enunciativa (FE), função que propícia a descrição dos enunciados como acontecimentos discursivos únicos.

Primeiramente, traço algumas considerações sobre o método arqueológico de Foucault demonstrando porque ele pode ser um dispositivo de leitura. $\mathrm{Na}$ sequência, descrevo as particularidades da formação discursiva segundo Foucault (FD), depois faço a análise de exercícios propostos para trabalho com o gênero discursivo notícia do LDEM (Cereja \& Magalhães, 2005) e finalizo com a proposta de atividades complementares de interpretação.

\section{A arqueologia de Foucault: noções para interpretação dos discursos}

Para Gregolin (2003), o livro Arqueologia do saber, no qual estão presentes as noções de Formação discursiva de Foucault, é um livro de caráter teóricometodológico, em que o autor sistematiza uma série de conceitos basilares para a abordagem do discurso. Esse aporte teórico trata o texto na sua articulação com a exterioridade, tendo em vista que, a produção de sentidos não está somente na constituição interna da palavra ou no texto como uma unidade, mas na relação com as regras históricas que determinaram e possibilitaram a emergência desse texto, e não de outros em seu lugar.

Sob esse horizonte, a análise e a interpretação de um texto têm como principio de observação a circunstância da enunciação do mesmo, além de considerar sua constituição estrutural linguística. O campo enunciativo de um texto é determinado, em parte, pela linguagem e, em parte, por determinantes histórico-discursivos. De um lado, há as possibilidades e escolhas linguísticas e, de outro, há regras históricas que estabelecem as condições de emergência e existência do fato enunciado. Essas condições são primordiais para a materialização dos enunciados, uma vez que não se pode falar de tudo em qualquer circunstância ou em qualquer período, "qualquer um, enfim, não pode falar de qualquer coisa" (Foucault, 2008b, p.9), assim como,

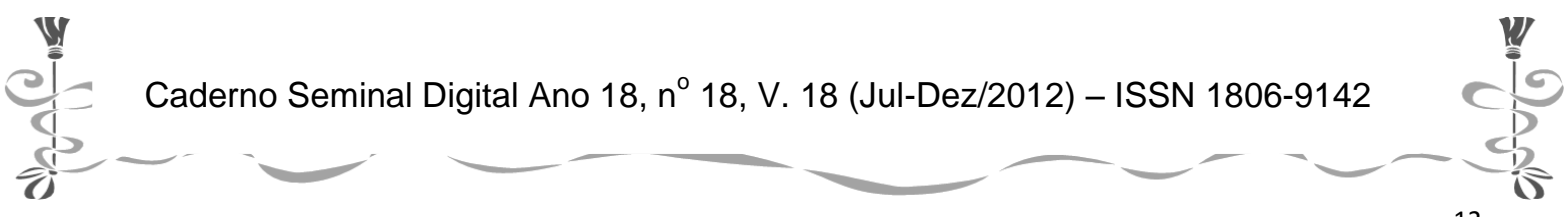




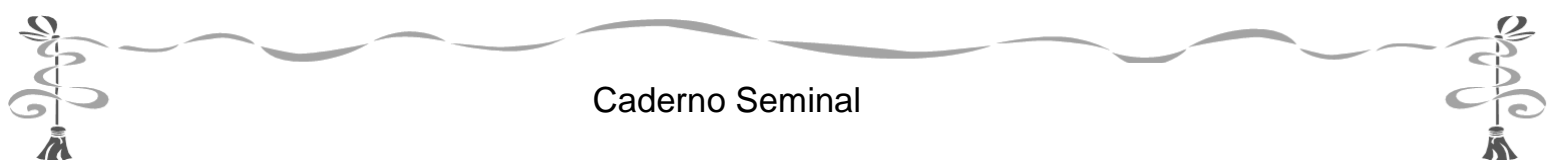

"não é fácil dizer alguma coisa nova; não basta abrir os olhos, prestar atenção, ou tomar consciência”, para se discorrer sobre novos assuntos (Foucault, 2008a, p.50).

Desse modo, um texto carrega traços distintivos fundamentais ou resquícios do tempo em que foi enunciado. Para Maingueneau (1996), todo enunciado é o produto de um acontecimento discursivo único, que define uma situação. A partir desse princípio, um texto apresenta certas particularidades que o caracteriza como um acontecimento discursivo exclusivo, do qual só ocorre um. Nesse trabalho, portanto, o texto é compreendido como enunciado seja ele verbal, visual ou multimodal.

Tendo em vista a singularidade de qualquer enunciado, devido ao campo particular de sua produção, a descrição de um contexto enunciativo permite estudar o texto a partir de sua constituição estrutural linguística e também a partir das regras de enunciação extralinguística do discurso. Tal perspectiva diferencia-se da linguística imanente, que estuda a língua unicamente a partir do princípio de suas regularidades estruturais internas, "o que permite apreendê-la na sua totalidade, já que as influências externas geradoras de irregularidades, não afetam o sistema por não serem consideradas como parte da estrutura" (Mussalim, 2001, p. 103).

Compreendida como um dispositivo de leitura e interpretação de texto, a AD é uma ciência que trabalha "como" o texto funciona e produz sentidos e não com a posição tradicional de análise de conteúdo que busca compreender "o que" o texto quer dizer. $\mathrm{Na}$ perspectiva foucaultiana, a análise enunciativa é, pois, uma análise histórica: aos enunciados pergunta-se "de que modo existem, o que significa para eles o fato de se terem manifestado, de terem deixado rastros e, talvez, de permanecerem para uma reutilização eventual"; o que é para eles o fato de terem aparecido - e nenhum outro em seu lugar (Foucault, 2008a, p. 124).

Essa linha de estudos apresenta uma concepção especial sobre o sentido, para Análise do Discurso (AD) o sentido não é universal ou convencional, uma vez que não é necessariamente expresso em sua totalidade (Orlandi, 2001). Para a AD um enunciado, um discurso ou uma palavra não têm um só sentido, visto que a produção de efeitos de sentidos não está apenas nas palavras ou nos textos, mas na sua relação com a exterioridade e a memória e nas condições histórica em que eles são produzidos. Desse modo, a interpretação textual se pauta nos processos e nas condições de produção da linguagem, por meio da relação estabelecida entre língua e os sujeitos que a falam e as situações em que se produz o dizer. A partir dessa perspectiva, o estudo e interpretação discursiva têm o enunciado como objeto de observação e descrição.

\section{O enunciado foucaultiano: objeto de análise e interpretação discursiva}

O enunciado, objeto de análise e interpretação discursiva, não apresenta uma forma única, nem é fácil de descrever. Definir um enunciado, materialidade de análise do

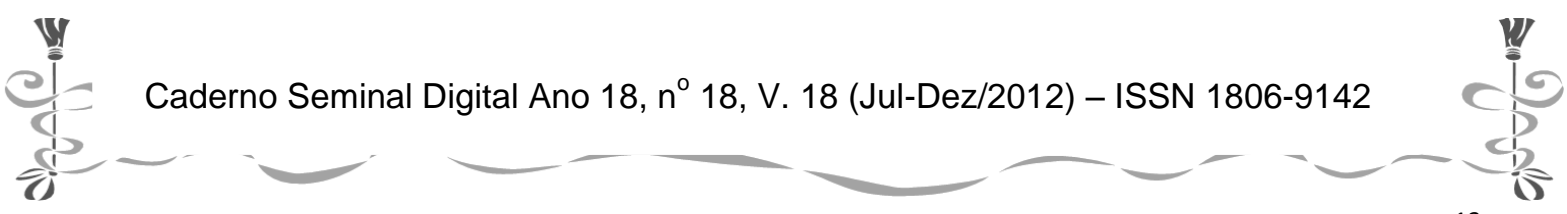




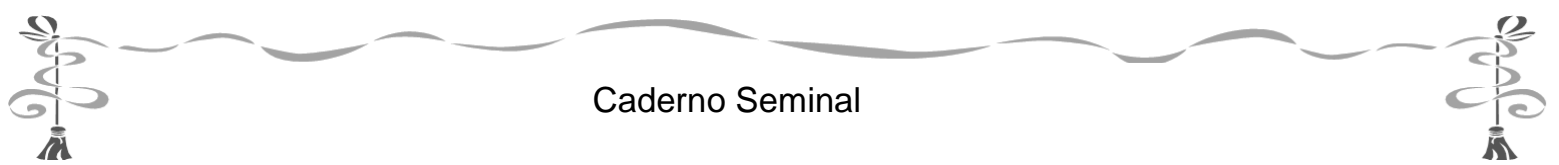

discurso, é uma tarefa bastante complexa, ele não tem limites precisos, não se mostra numa unidade atômica ou elementar e nem apresenta independência.

A dificuldade de delimitá-lo está nos fatos de que há enunciados sem estrutura proposicional fidedigna, ou seja, o enunciado não é a proposição dos estudos da lógica; há enunciados sem os elementos essenciais de uma frase; há enunciado que sozinho constitui um ato ilocucionário, por outro lado, há atos ilocucionários que "só podem ser considerados acabados em sua unidade singular se vários enunciados tiverem sido articulados, cada um no lugar que lhe convém” (Foucault, 2008a, p. 94). Desse modo, em que nível situar os enunciados? Que método usar para abordálos?

O enunciado não é uma unidade fácil de ser estabelecida, contudo "o campo de exercício da função enunciativa e as condições segundo as quais aparecem unidades diversas" constituem as condições de possibilidade para descrevê-lo (Foucault, 2008a, p.120-121).

$\mathrm{Na}$ perspectiva foucaultiana, o enunciado exerce o papel de uma função de existência, e que pertence, exclusivamente, aos signos; ele é definido pelos quatro conjuntos de regras que caracterizam a formação discursiva: formação das modalidades enunciativas, formação dos objetos, formação do conceito e formação das estratégias ou tema. Ele é um corpo visível de uma sequência decorrente de um processo de enunciação; é constituído, portanto, de uma materialidade de signo(s) que foi efetivamente produzida, moldada, delineada, fabricada, traçada, articulada, no tempo e no espaço.

Para os estudos gramaticais uma unidade elementar pode ser isolada em uma frase ou em uma proposição, descrever essas unidades significa isolá-las e caracterizá-las gramatical e estruturalmente. Entretanto, nos estudos discursivos, descrever um enunciado significa definir as condições pelas quais uma série de elementos sígnicos apresentou uma existência específica.

A função enunciativa, ao por em jogo unidades diversas, não atribui um "sentido" para a unidade do enunciado, mas o coloca em relação com um campo de objetos; ela também abre ao enunciado um conjunto de posições subjetivas possíveis ao invés de lhes conferir um sujeito único; não lhe coloca limites, mas o insere em um domínio de coordenação e de coexistência; não lhe atribui uma identidade, mas o aloja em um lugar em que é utilizado e repetido.

Conforme descrito, é a análise dos quatro elementos da formação discursiva que baliza as demarcações próprias do enunciado em sua especificidade.

\section{A formação discursiva segundo Foucault}

É relevante destacar, nesse momento, que as quatro direções em que se analisa a FD: a formação dos objetos, a formação das modalidades enunciativas, a formação dos conceitos e a formação das estratégias, correspondem, de maneira recíproca, aos

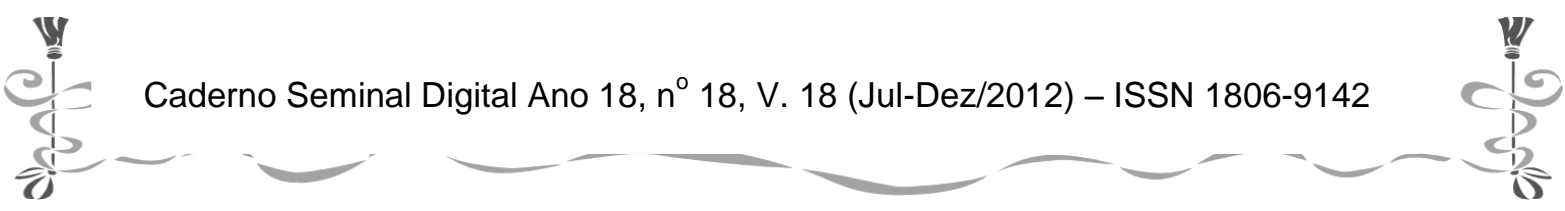




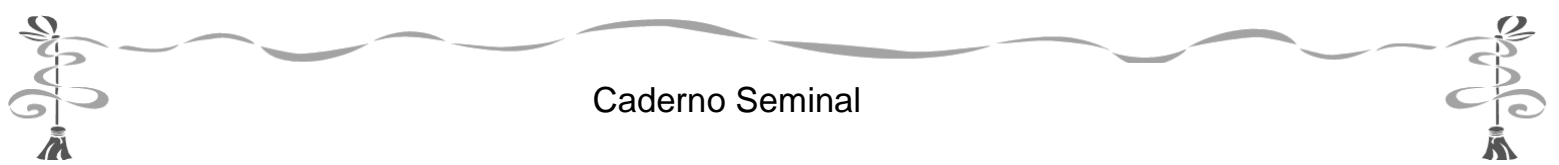

domínios em que se exerce a FE: o referencial, o sujeito, o domínio associado e a materialidade do enunciado. Desse modo, descrever os enunciados e a função enunciativa de que são portadores é tentar revelar uma formação discursiva individualizada, ou na direção inversa, demarcar a FD revela o nível específico enunciativo de um conjunto de enunciados.

Os objetos, os tipos de enunciação, os conceitos e as escolhas estratégicas, ou seja, as quatro regras de formações da FD, não são independentes umas em relação às outras. Há sempre um quadro de relações operante. Assim,

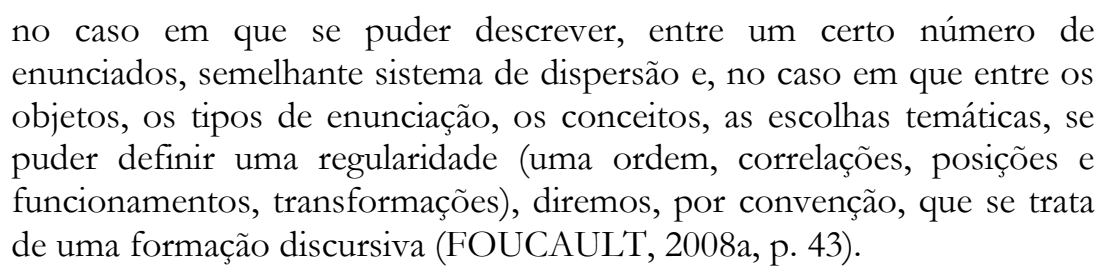

A formação discursiva é, portanto, a unidade que se constata nas regularidades entre objeto, conceito, teoria e sujeito, numa série de enunciados, o que permite definir, por exemplo, o discurso sobre a educação. Tal unidade não pode ser delimitada "por outras fronteiras senão aquelas estabelecidas pelo pesquisador; e elas devem ser especificadas historicamente. Os corpora aos quais elas correspondem podem conter um conjunto aberto de tipo e de gêneros do discurso, de campos e de aparelhos, de registro" (Maingueneau, 2006, p. 16).

Corrobora, nesse sentido, destacar o termo "formação" em "formação discursiva", cujo caráter dinâmico e ativo se opõe ao caráter estático e pronto, uma vez que as regras de formação não preexistem à análise. Em vez de considerar o termo formação "em uma perspectiva puramente estática como se referindo a uma entidade já existente, o analista, em função de sua pesquisa, dá forma a uma configuração original" (Maingueneau, 2006, p.19). O dinamismo de cada regra de formação, com suas falhas e trocas, é o que torna possível conceber as regularidades de uma unidade discursiva num sistema de dispersão de enunciados. Assim, "se há unidade, ela não está na coerência visível e horizontal dos elementos formados; reside, muito antes, no sistema que torna possível e rege sua formação" (Foucault, 2008a, p. 80).

\section{Do livro didático à constituição de um dispositivo de leitura}

O livro didático (LD) é o material educativo mais utilizado na escola brasileira atualmente, uma vez que, além de auxiliar a prática pedagógica do professor, ele representa, na maioria das vezes, a única fonte de informação científica para o estudante das escolas públicas brasileiras (Carmagnani, 1999; Souza, 1999). O LD é um instrumento pedagógico adotado pela escola e destinado ao ensino; é um livro cujo conteúdo expõe total ou parcialmente a matéria das disciplinas dos programas

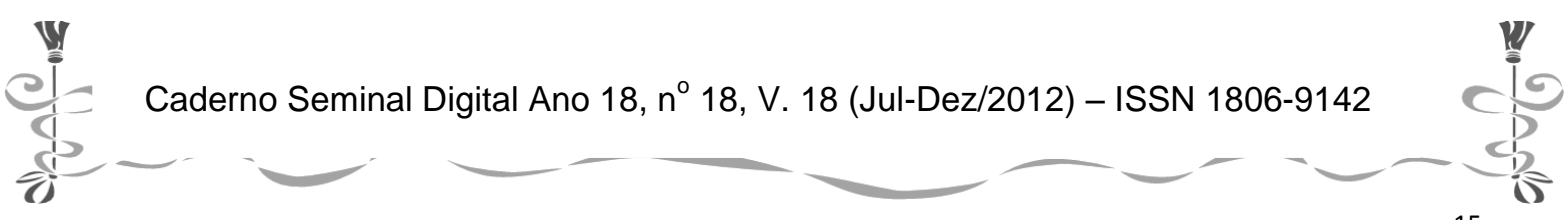




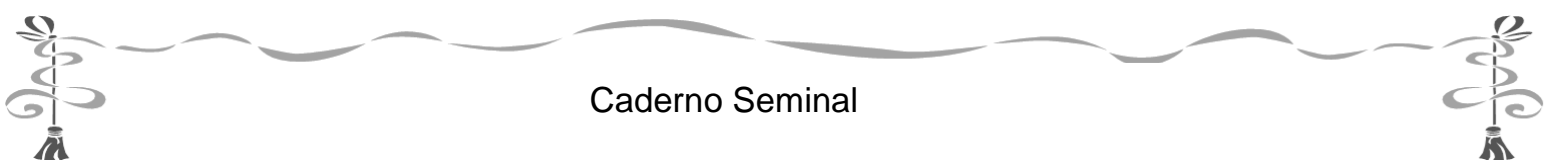

escolares e sua proposta deve estar de acordo com os parâmetros divulgados nos documentos oficiais, tais como os Parâmetros curriculares nacionais (PCN).

Em sala de aula, esse material dispõe ao professor e aos alunos um conjunto de textos e exercícios com base nos quais o ensino e o aprendizado podem tomar direcionamento. Para o estudante, o LD também se constitui num dispositivo de apoio ao estudo autônomo fora de sala de aula e para muitos ele é o único material escrito de base letrada que poderão ter em casa.

No livro didático de Cereja \& Magalhães (2005), as atividades referentes ao estudo do texto estão voltadas para a identificação, reconhecimento e a produção de gêneros discursivos, além de buscar reconhecer o padrão linguístico presente no texto. Por sua vez, a leitura não tem prioridade nas atividades propostas.

Tomo como exemplo o capítulo 27 do livro para o $2^{\circ}$ ano do ensino médio que trata do gênero discursivo notícia. A proposta de trabalho com esse gênero articula atividades que versam sobre a identificação da estrutura composicional da notícia, figura 1, e sobre as características peculiares desse gênero, figura 2.

O anúncio publicitário geralmente é constituído de linguagem verbal e de linguagem não verbal. Que relação há entre a imagem e o texto principal do anúncio: "Colocar uma criança para trabalhar na sua casa é tirar a infância e o futuro dela"?

Leia o texto disposto logo abaixo da imagem principal do anúncio. Qual é a finalidade desse texto?

O anúncio publicitário é um gênero textual que tem a finalidade de promover uma idéia, a marca de um produto ou o nome de uma empresa. Os anúncios publicitários mais conhecidos são os comerciais, que circulam na TV, no rádio, em jornais e revistas.

a) O anúncio lido promove uma idéia ou a marca de um produto?

b) Que produto ou idéia ele promove?

c) Quem é o locutor desse anúncio, ou seja, de quem foi a iniciativa de publicar esse anúncio? Justifique sua resposta com elementos do próprio anúncio.

FIGURA 1

EXERCíCIOS RETIRADOS DO LIVRO DIDÁTICO PARA O 2 ANO DO ENSINO MÉDIO DE PORTUGUÊS (CEREJA \& MAGALHÃES, 2005), DO TRIÊNIO 2009/2011.

Como é possível observar nesses exercícios, os estudos com texto primam pela identificação dos elementos essenciais do gênero discursivo e o reconhecimento dessas partes no interior do texto, mas não propõe ao aluno refletir a respeito do acontecimento discursivo.

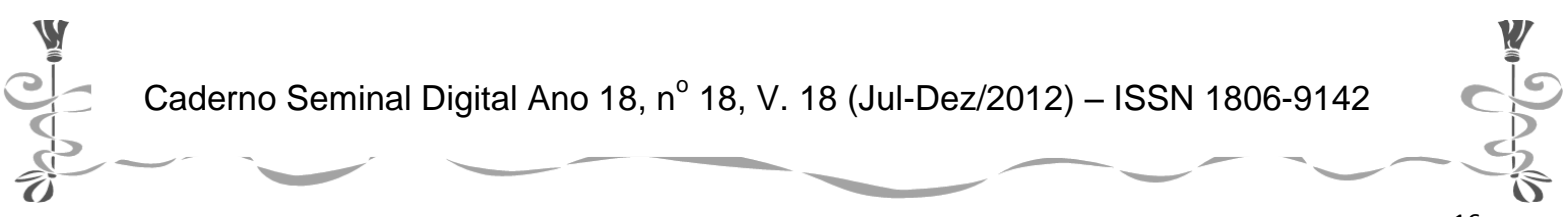




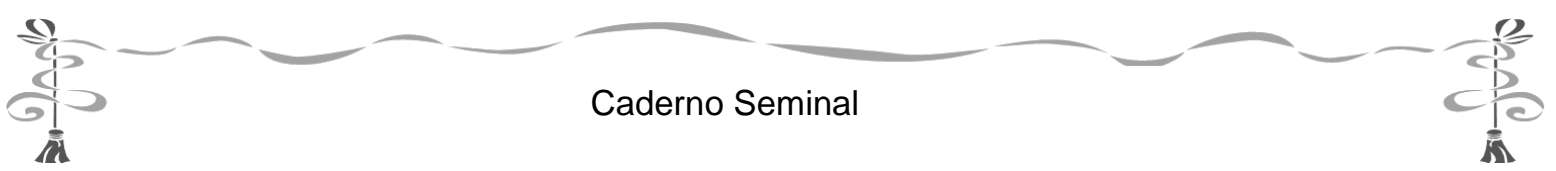

Na parte inferior do anúncio, à esquerda, há um texto em letra menor, onde se lê:

"Quando você abre a porta de sua casa para uma criança trabalhar, você fecha muitas outras, como o estudo, o lazer, o convívio familiar, o desenvolvimento. Sem contar os riscos a que ela se expõe ao cuidar de uma casa. 0 trabalho infantil também tira da criança o que ela tem de mais precioso: sua infância. Diga não ao trabalho infantil doméstico. O respeito pela criança e pelo adolescente começa dentro da sua casa."

a) Qual é a função desse texto?

b) Que figura(s) de linguagem foi (foram) empregada(s) na frase: “Quando você abre a porta de sua casa para uma criança trabalhar, você fecha muitas outras"?

Reúna-se com seus colegas de grupo e, juntos, respondam: Quais são as principais características de um anúncio publicitário?

FIGURA 2

EXERCÍCIOS RETIRADOS DO LIVRO DIDÁTICO PARA O 2 ANO DO ENSINO MÉDIO DE PORTUGUÊS (CEREJA \& MAGALHÃES, 2005), DO TRIÊNIO 2009/2011.

Os exercícios, na sua maioria, relacionam-se às qualidades fundamentais do gênero notícia e primam pelo reconhecimento da estrutura interna do gênero. Dentre as atividades com texto, destacam-se também aquelas que trabalham com a linguagem verbal, nesses exercícios, quer-se reconhecer o padrão e as características da linguagem usada no gênero discursivo, figura 3, mas não se propõe pensar em seus sentidos.

O anúncio publicitário é um gênero textual do grupo dos gêneros argumentativos, pois tem a finalidade de convencer o leitor a consumir determinado produto ou aderir a certa idéia. A linguagem geralmente se adapta ao perfil do público e freqüentemente apresenta verbos no imperativo ou no presente do indicativo.

a) No anúncio em estudo, que tipo de variedade lingüística foi empregada?

b) Nas frases "Não leve essa idéia para dentro da sua casa" e "Diga não ao trabalho infantil doméstico", que modo verbal foi empregado?

c) Com que intenção o anunciante empregou esse modo verbal?

d) Na frase da parte superior do anúncio, o verbo está empregado no infinitivo - colocar. Como ficaria a frase, caso o anunciante optasse por empregar o imperativo?

e) Levante hipóteses: Por que o anunciante optou pela forma infinitiva, no texto principal do anúncio, em vez do imperativo?

\section{FIGURA 3}

EXERCÍCIOS RETIRADOS DO LIVRO DIDÁTICO PARA O 2 ANO DO ENSINO MÉDIO DE PORTUGUÊS (CEREJA \& MAGALHÃES, 2005), DO TRIÊNIO 2009/2011.

Todas essas atividades têm relevância no processo de ensino e aprendizagem da língua, no entanto, há lacunas quanto a uma questão muito relevante nesse processo, a interpretação. A leitura aparece, apenas uma vez no capítulo, como uma atividade individual de coleta de informações para produção escrita,

Ao escrever sua notícia, siga as instruções:

Faça um planejamento. Leia jornais e revistas, depois converse com seus pais, professores, colegas e vizinhos sobre o assunto escolhido, procurando obter o maior número possível de informações (CEREJA \& MAGALHÃES, 2005, p.243).

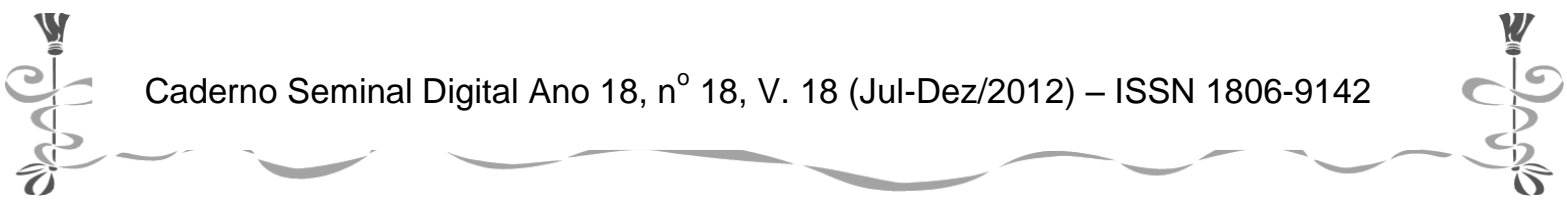




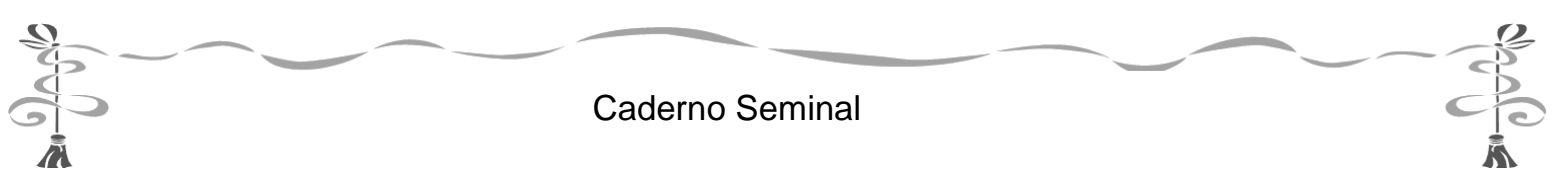

Reúna-se com seus colegas de grupo para, juntos, escreverem um anúncio publicitário. Antes, porém, leiam o texto a seguir [...] (CEREJA \& MAGALHÃES, 2005, p.344).

Entretanto, a leitura de gêneros discursivos na escola por meio da mediação de um professor pode conduzir a diferentes efeitos de sentido, permitindo ao aluno seu posicionamento enquanto sujeito ativo. A atividade de leitura no trabalho com os gêneros discursivos precisa ser a primeira entre todas as outras. Por meio da interpretação os alunos podem ser levados a refletir sobre a linguagem e a aprender a língua.

Contrariamente, nas aulas de línguas, o texto é, na maioria das vezes, usado como pretex to para o estudo das características do gênero discursivo, da gramática, ou de

outro aspecto da linguagem que o professor (ou o livro didático) reputam como importante ensinar. Assim, o texto, parte do material didático, perde a sua função essencial de provocar efeitos de sentido no leitor-aluno, para ser apenas o lugar de reconhecimento de unidades e estruturas linguísticas cuja funcionalidade parece prescindir dos sujeitos (CORACINI, 1999, p.18)

No modo como o livro didático de Cereja \& Magalhães concebe o trabalho com o gênero discursivo não há uma relação entre as atividades de leitura, de gramática e de produção da escrita. Ademais, na totalidade do capítulo analisado não há preocupação em formar um "conjunto de referências" sobre o objeto do discurso como apoio à produção textual solicitada. Desse modo, a proposta dos autores do livro didático é lacunar quanto à formação do aluno como sujeito-leitor de textos na escola e na sociedade.

Sob tais condições, propõe-se, nesse texto, um complemento para o encaminhamento das atividades com o gênero discursivo, sugere-se um dispositivo de leitura que se constitui num espaço no qual o aluno se coloca como sujeito.

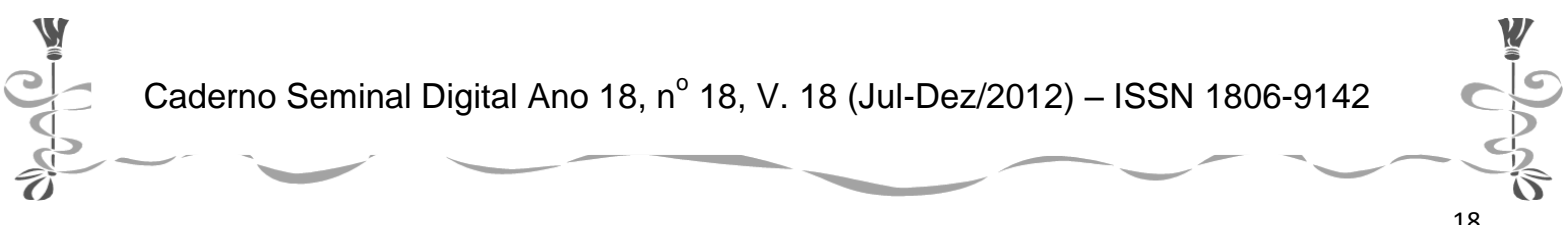



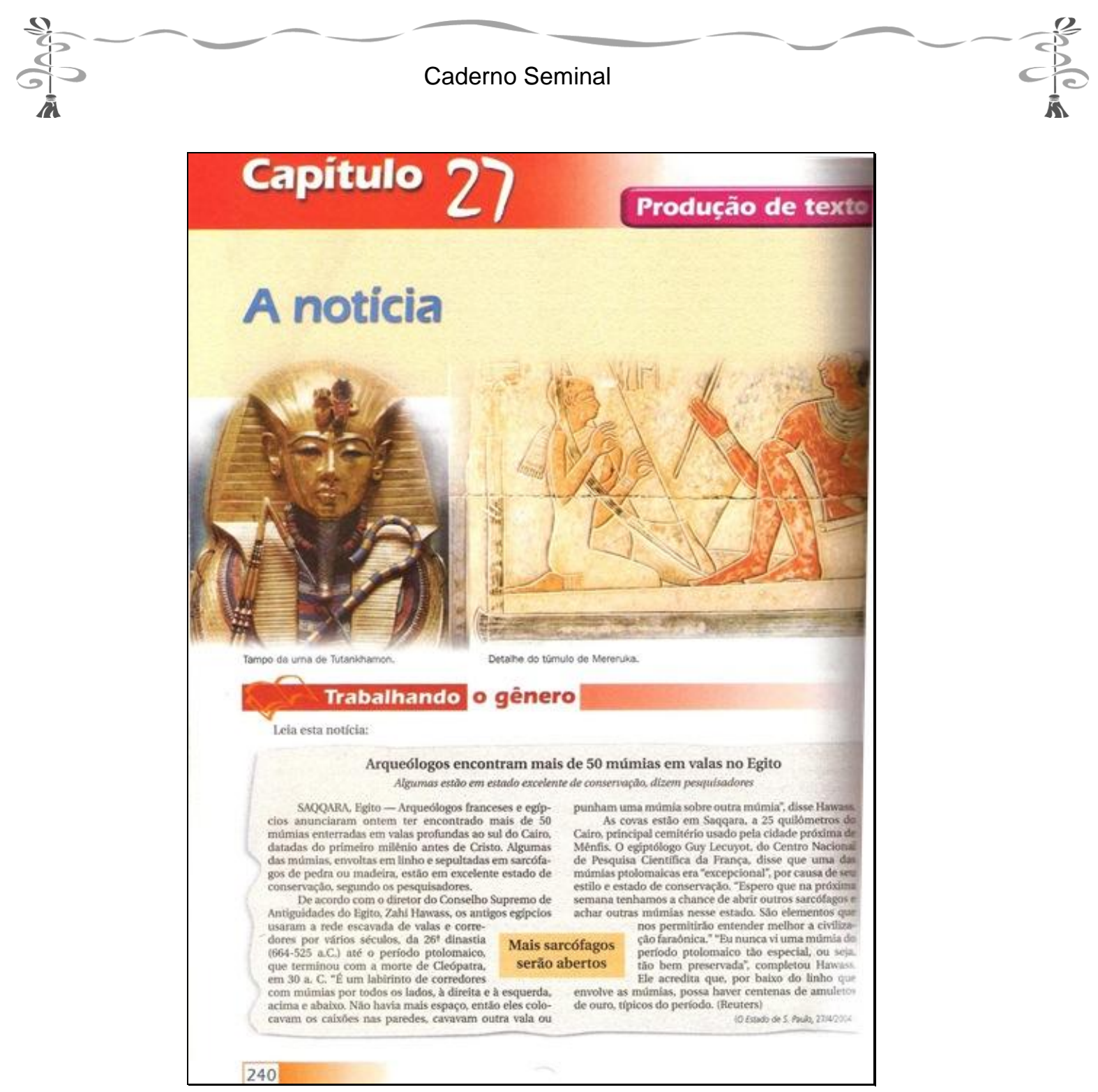

FIGURA 4

EXERCÍCIOS RETIRADOS DO LIVRO DIDÁTICO PARA O 2 ANO DO ENSINO MÉDIO DE PORTUGUÊS (CEREJA \& MAGALHÃES, 2005), DO TRIÊNIO 2009/2011.

Tendo em vista os enunciados da figura 5, proponho um dispositivo teóricoanalítico de interpretação do discurso com base na noção de Formação discursiva de Foucault, que leva em consideração a descrição do campo enunciativo do enunciado. Desse modo, convém questionar sobre as quatro regras de formação de uma FD, com vistas a delimitar o quadro enunciativo. Os exemplos dados na tabela 1 se constituem em uma possibilidade de efeito de sentidos, no entanto, outros sentidos podem ser construídos. O objeto do discurso, por exemplo, pode ser a múmia, o Egito, a cultura egípcia, a morte, o corpo humano entre outros.

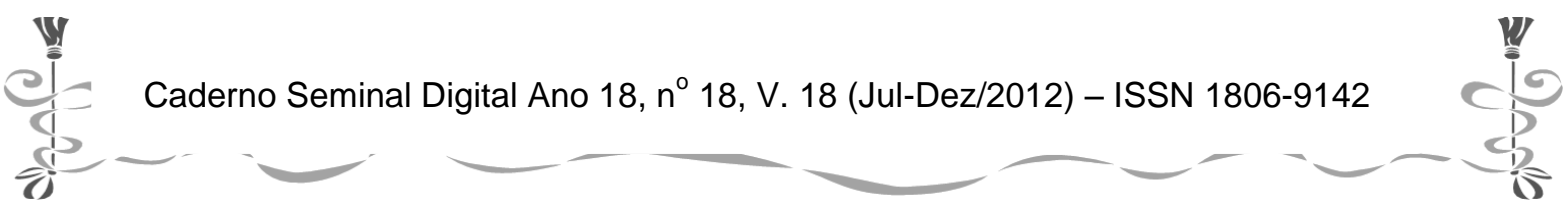




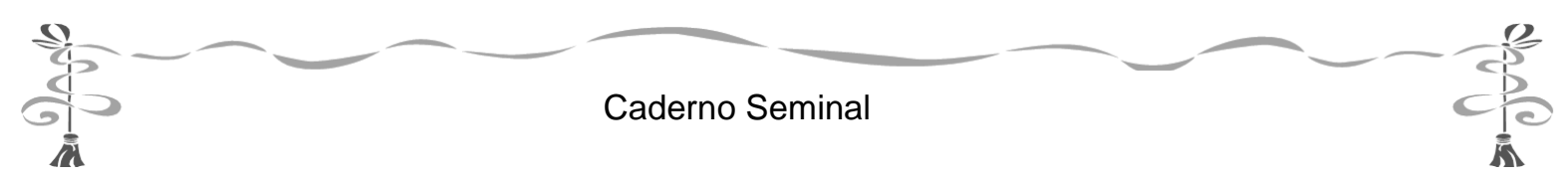

\begin{tabular}{|l|l|}
\hline \multicolumn{2}{|c|}{ Dispositivo teórico para questionamento do texto } \\
\hline Objeto & $\begin{array}{l}\text { Qual é o as sunto do texto? Em quais instituições } \\
\text { sociais se fala desse assunto, tendo em vista o texto } \\
\text { lido? }\end{array}$ \\
\hline Suj eito & $\begin{array}{l}\text { Quem produziu o texto/Qual é a profissão desse } \\
\text { sujeito? Para que tipo de empresa esse sujeito } \\
\text { trabalha? Outro sujeito poderia falar desse assunto? } \\
\text { Por quê? }\end{array}$ \\
\hline Conceito & $\begin{array}{l}\text { Qual(s) conceito(s) do assunto é (são) } \\
\text { discutido(s)/apresentado(s) no texto? Com quais } \\
\text { outros assuntos, o assunto do texto tem ou teve } \\
\text { relação próxima? }\end{array}$ \\
\hline Teoria & $\begin{array}{l}\text { Sob qual área do conhecimento o assunto (do texto) } \\
\text { é abordado? Por que esse assunto é abordado sob tal } \\
\text { área do conhecim ento e não sob outra? }\end{array}$ \\
\hline
\end{tabular}

\section{TABELA 1 \\ FUNÇÃO ENUNCIATIVA/FORMAÇÃO DISCURSIVA -QUADRO TEÓRICO-METODOLÓGICO PARA INTERPRETAÇÃO DOS DISCURSOS}

Desse modo, a partir das definições dessas quatro noções que se revezam, podemos descrever regularidades em certos conjuntos de enunciados. Contudo, além de determinar essas quatro unidades, o estudante pode ser levado a refletir sobre outras possibilidades discursivas sobre esses elementos e inventariar porque apareceu esse enunciado e não outro em seu lugar. Sob essa perspectiva, professor e estudantes podem ser movidos a pensar:

\footnotetext{
em que tipo de gênero discursivo é possível encontrar conteúdo sobre o mesmo objeto? Ex.: Artigo científico, notícia, reportagem;

por que quem que fala sobre tal objeto é o sujeito $X$ ? Poderia outro sujeito falar sobre o mesmo objeto?;

o objeto em estudo tem outro conceito? Qual? Por que esse(s) outro(s) conceito(s) não apareceram no texto estudado? Em quais gêneros discursivos esse(s) outro(s) conceito(s) poderiam aparecer?;

poderia esse objeto ser tratado por outra teoria ou área de conhecimento? Qual? Afinal, vale questionar: porque apareceu esse enunciado e nenhum outro em seu lugar?
}

Ao determinar essas regularidades referentes ao enunciado estudado, delimita-se de onde ele vem e porque ele apareceu em detrimento às outras possibilidades temáticas. Tendo isso em vista, após interpretar o enunciado primeiro, propõe-se realizar ainda outras pesquisas leitoras que envolvam os elementos da formação discursiva estudada:

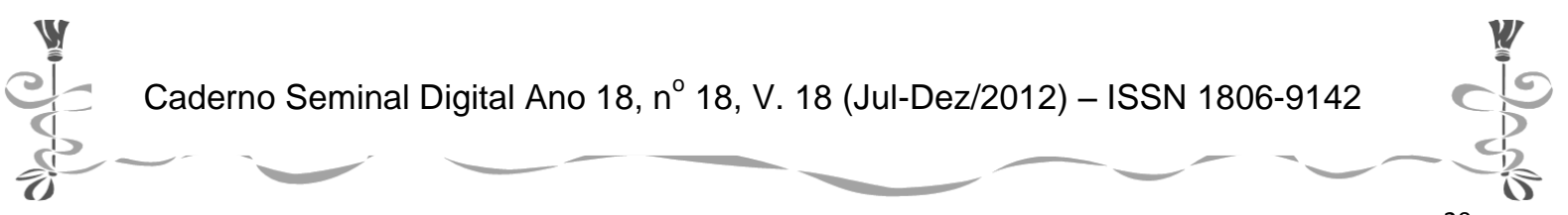




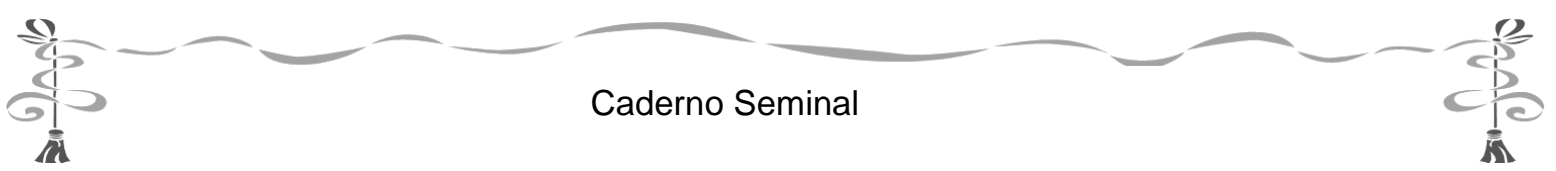

procurar outra notícia que trate do mesmo objeto sob a mesma perspectiva conceitual; pesquisar outro gênero discursivo cujo sujeito-enunciador seja o mesmo do gênero estudado (ex. o arqueólogo ou o historiador);

procurar um texto que trate da mesma ciência, a arqueologia.

Desse modo, procura-se evidenciar o modo como o discurso funciona. Para Foucault, "os discursos são uma dispersão, ou seja, são formados por elementos que não estão ligados por nenhum princípio de unidade a priori, cabendo à análise do Discurso, descrever essa dispersão, buscando as 'regras de formação' que regem uma FD”. Assim, as formações discursivas são, pois, essa regularidade que pode ser descrita no caso em que, entre os enunciados, vislumbre-se o funcionamento de um sistema de dispersão, e no caso em que entre os objetos, os tipos de enunciação, os conceitos, as escolhas temáticas, se puder definir uma regularidade, ordem, correlações, posições, funcionamentos e transformações. Esta descrição de regularidades se propõe a estudar as formas de repartição e os sistemas de dispersão dos acontecimentos enunciativos, possibilitando a passagem da dispersão para a regularidade (Grangeiro, s/d, p. 02-03). Desse modo, a partir das definições dessas quatro noções que se revezam podemos descrever regularidades em certos conjuntos de enunciados.

\section{Considerações finais}

Tendo em vista o objetivo desse texto, a análise dos exercícios do capítulo 27, Cereja \& Magalhães (2005), demonstrou que as atividades primam pelo trabalho exclusivo com as singularidades linguísticas, organização, disposição e ordem dos elementos do gênero discursivo em detrimento do exercício de leitura do texto. Ademais, as atividades não problematizam o porquê do estudo do gênero discursivo em questão e nem o porquê da escolha do mesmo. O texto visual e o multimodal, presentes na página inicial - fotografia e fotolegenda - não são percebidos como textos e, parecem funcionar apenas figurativamente, uma vez que não há atividades que os envolvam. Portanto, o capítulo todo aponta mais para a estrutura do gênero discursivo e não apresenta atividade de compreensão.

Considera-se, portanto, que a escolha do livro didático é relevante, uma vez que nem todas as referências bibliográficas aprovadas pelo PNLD ou de acordo com os PCN asseguram coerência entre pressupostos teóricos e práticas metodológicas do LD.

Há muitos materiais que, por exemplo, usam o texto como pretexto, embora os Parâmetros Curriculares Nacionais, desde 1998, difundam a orientação discursiva para o ensino de língua portuguesa, a qual se fundamenta em parte na teoria dos gêneros discursivos de Bakhtin (1992) e, por outro lado, requer uma orientação discursiva de texto (Brasil, 1998). Perceber o texto como discurso é compreender que ele não encerra um sentido único. Nessa perspectiva, os diferentes modos de

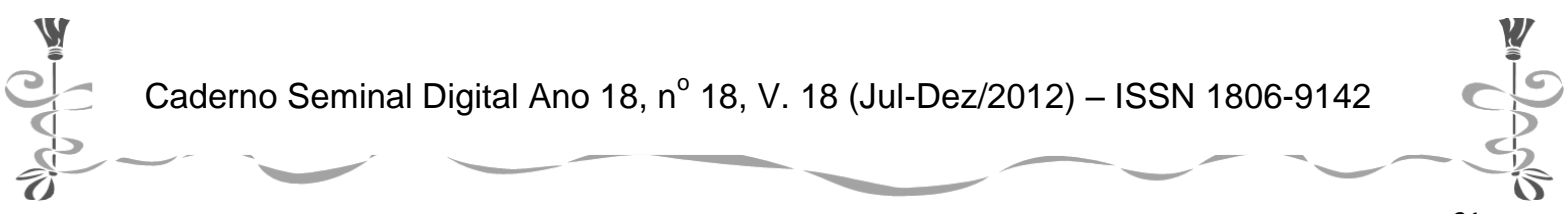




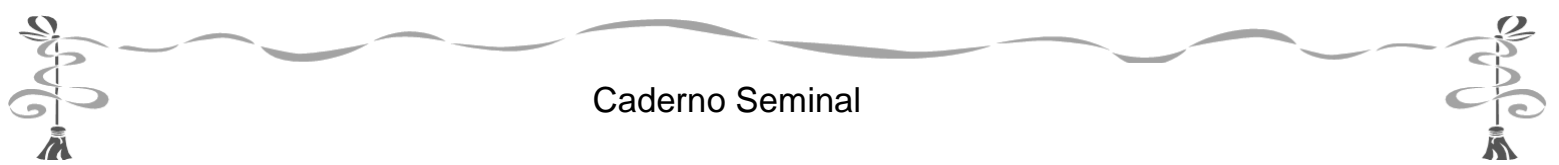

interpretação do texto e a produção de diferentes sentidos são aceitos como possibilidades.

Sob essa perspectiva, proposta metodológico-analítica, pelo viés da Análise do Discurso francesa (Foucault, 2008a), de interpretação textual pode ser incluída entre as atividades propostas pelos autores do livro didático e deve contribuir para que os alunos possam melhorar suas habilidades de leitura.

Os alunos-leitores podem ser levados a realizar, a princípio, uma leitura global do texto por meio da ativação de conhecimento prévio sobre o tema. E, posteriormente, fazer uma leitura detalhada do texto verbal e não verbal por meio da descrição das quatro unidades da formação discursiva, levando-se em consideração o gênero discursivo a que pertence o texto e as características da linguagem.

Determinar os quatro domínios do método arqueológico que constitui a identidade de uma formação discursiva juntamente com os aspectos estruturais linguísticos pode conduzir a leitura do texto e a diferentes efeitos de sentido, permitindo ao aluno se posicionar como sujeito ativo. As regras que constituem uma formação discursiva possibilitam ao leitor perceber o texto como discurso e que ele se relaciona a um exterior; permite compreender a singularidade da situação do enunciado, evidenciando por que não poderia ser outro; mostra como ele exclui qualquer outro, como ocupa, no meio dos outros enunciados e relacionados a eles, um lugar que nenhum outro poderia ocupar; estabelece também suas correlações com os outros enunciados a que pode estar ligado.

\section{Referências}

BAKHTIN, M. Estética da criação verbal. Trad. Maria Ermanita G. G. Pereira. São Paulo: Martins fontes, 1992.

BRASIL. Secretaria de Educação Fundamental. Parâmetros Curriculares Nacionais: língua portuguesa. Brasilia: MEC/SEF, 1998.

CARMAGNANI, A concepção de professor e de aluno no livro didático e o ensino de redação em LM e LE. In: Interpretação, autoria e legitimação do livro didático. CORACINI, M. J. (org.) Campinas SP: Pontes. Editora da Universidade Estadual de Campinas, 1999.

CEREJA, W. R.; MAGALHÃES, T. C. Português: linguagens. Vol. 2: ensino médio. 5 ed. São Paulo: Atual, 2005.

CORACINI, M. Leitura: decodificação, processo discursivo...? In: O jogo discursivo na aula de leitura: língua materna e língua estrangeira. CORACINI, M. J. (org.) Campinas, SP: Pontes. Editora da Universidade Estadual de Campinas, 1999.

GRANJEIRO, C. R. P. A propósito do conceito de formação discursiva em Michel Foucault e Michel Pêcheux. Disponível em < http: //www.discurso.ufrgs.br/sead2/doc/claudiagrangeiro.pdf $>$ Acesso em 16/08/2011.

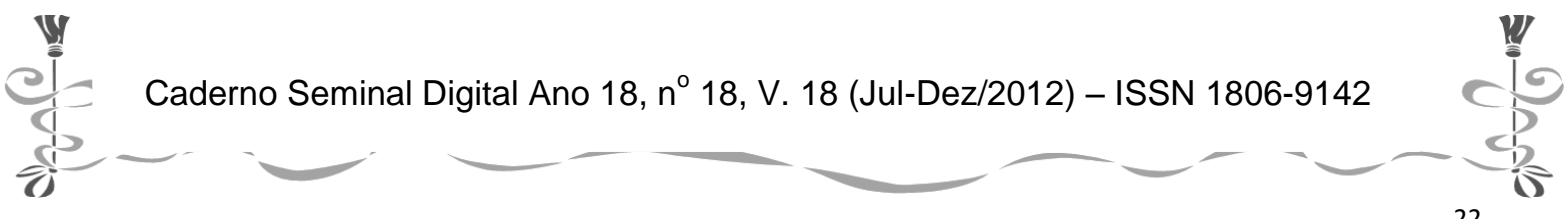




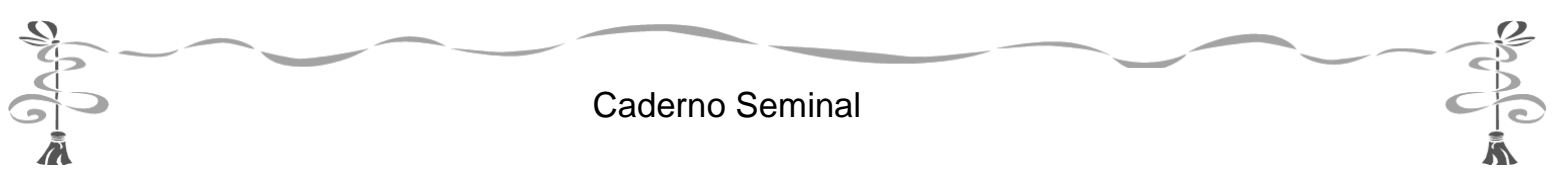

FOUCAUlT, M. A arqueologia do saber. 7 ed. Trad. Luiz F. B. Neves. Rio de Janeiro: Forense Universitária, 2008a. A ordem do discurso. 16 ed. Trad. Laura Fraga de Almeida. São Paulo: Loyola, 2008b.

MAINGUENEAU, D. Novas tendências em Análise do Discurso. 3 ed. Trad. Freda Indursky: Campinas SP: Pontes. Editora da Universidade Estadual de Campinas, 1996.

MAINGUENEAU, D. Unidades tópicas e não tópicas. In: POSSENTI; S SOUZA-ESILVA, M. C. P. (org.) Cenas da enunciação. Campinas, pp. 9-24, Criar, 2006.

MUSSALIM, F. Análise do Discurso. In: MUSSALIM, F. (org.) e BENTES, A. C. (org.) Introdução à linguística: dominios e fronteiras, V. 2, 2 ed., São Paulo: Cortez, 2001.

ORLANDI, E. P. Discurso e texto: formulação e circulação de sentidos. Campinas SP: Pontes. Editora da Universidade Estadual de Campinas, 2001.

SOUZA, D. Livro didático: arma pedagógica? In: CORACINI, M. J. (org.) Interpretação, autoria e legitimação do livro didático. Campinas SP: Pontes. Editora da Universidade Estadual de Campinas, 1999. 